\title{
A Comparative Study on Structural and Optical Properties of ZnO Micro- Nanorod Arrays Grown on Seed Layers Using Chemical Bath Deposition and Spin Coating Methods
}

\author{
Sibel MORKOÇ KARADENIZ ${ }^{1}$ *, Burcu BOZKURT ÇIRAK ${ }^{2}$, Tuba KILINÇ ${ }^{1}$, \\ Çağrı ÇIRAK ${ }^{1}$, Murat İNAL ${ }^{1}$, Zeynep TURGUT ${ }^{1}$, Ali Ercan EKİNCI ${ }^{1}$, \\ Mehmet ERTUĞRUL ${ }^{3}$
}

\author{
${ }^{1}$ Department of Physics, Erzincan University, Erzincan 24000, Turkey \\ ${ }^{2}$ Department of Alternative Energy Sources, Vocational School, Erzincan University, Erzincan 24000, Turkey \\ ${ }^{3}$ Department of Electrical and Electronics Engineering, Atatürk University, Erzurum 25040, Turkey \\ cross $^{\text {ref }}$ http://dx.doi.org/10.5755/j01.ms.22.4.13443
}

Received 24 October 2015; accepted 19 February 2016

\begin{abstract}
In this study, Zinc Oxide ( $\mathrm{ZnO})$ seed layers were prepared on Indium Tin Oxide (ITO) substrates by using Chemical Bath Deposition (CBD) method and Sol-gel Spin Coating (SC) method. ZnO micro-nanorod arrays were grown on $\mathrm{ZnO}$ seed layers by using Hydrothermal Synthesis method. Seed layer effects of structural and optical properties of $\mathrm{ZnO}$ arrays were characterized. X-ray diffractometer (XRD), Scanning Electron Microscopy (SEM) and Ultraviolet Visible (UV-Vis) Spectrometer were used for analyses. ZnO micro-nanorod arrays consisted of a single crystalline wurtzite $\mathrm{ZnO}$ structure for each seed layer. Besides, $\mathrm{ZnO}$ rod arrays were grown smoothly and vertically on SC seed layer, while $\mathrm{ZnO}$ rod arrays were grown randomly and flower like structures on CBD seed layer. The optical absorbance peaks found at $422 \mathrm{~nm}$ wavelength in the visible region for both $\mathrm{ZnO}$ arrays. Optical bandgap values were determined by using UV-Vis measurements at 3.12 and $3.15 \mathrm{eV}$ for $\mathrm{ZnO}$ micro-nanorod arrays on CBD seed layer and for $\mathrm{ZnO}$ micro-nanorod arrays on SC-seed layer respectively.

Keywords: $\mathrm{ZnO}$, micro-nanorod, chemical bath deposition, spin coating, hydrothermal synthesis.
\end{abstract}

\section{INTRODUCTION}

In the past decades, well aligned nanostructures with controlled surface area and crystal morphologies have attracted a great interest, based on the fact that the morphologies of most nanostructures can effectively tune their intrinsic chemical and physical properties [1]. Zinc oxide $(\mathrm{ZnO})$, as a wide and a direct bandgap $(3.37 \mathrm{eV})$ semiconductor, has attracted much attention due to its novel optical and electronic properties [2]. While there are various $\mathrm{ZnO}$ nanostructures such as nanowire, nanorod, nanobelts, nanotube and nanoflowers, $\mathrm{ZnO}$ nanorod arrays draw attention because of their optical and electrical characteristics [3]. Well-aligned $\mathrm{ZnO}$ nanorod arrays are very popular due to their unique applications particularly for gas sensor [4], photoelectrochemical [5], photocatalytic devices [6], solar cells [7]. Some techniques, such as VLS [8], CVD [9], hydrothermal methods [10,11] were used for synthesis of $\mathrm{ZnO}$ arrays.

The CBD method has many advantages such as simplicity, low cost [12]. The sol-gel SC method has several advantages such as a broad deposition area, low cost for the technological applications and easy of use [13]. Hydrothermal synthesis which is a simple, easy and low cost method, is used for obtaining nanostructures in specific shape and size at lower temperatures (lower than $\left.100{ }^{\circ} \mathrm{C}\right)[10,14]$.

\footnotetext{
* Corresponding author. Tel.: +90-446-2243032/40036; fax: +90-4462243016. E-mail address: morkocsibel@gmail.com (S. Morkoç Karadeniz)
}

In order to prepare $\mathrm{ZnO}$ seed layers, $\mathrm{SC}$ method is generally used in the literature [14-17]. In addition, CBD method is not used as a seed layer synthesis method according to the research mentioned in the literature.

In this study, $\mathrm{ZnO}$ seed layer was synthesized by using $\mathrm{CBD}$ and SC methods. Then, $\mathrm{ZnO}$ micro-nanorod arrays were grown successfully on seed layers by using Hydrothermal Synthesis method.

The fundamental aim of this study is to investigate the effect of seed layer prepared with CBD method and SC method on $\mathrm{ZnO}$ micro-nanorod arrays.

\section{EXPERIMENTAL DETAILS}

In this study, $\mathrm{ZnO}$ seed layers were synthesized on Indium Tin Oxide (ITO) substrates, ITO has a high electrical conductivity, high optical transparency in the visible range and high infrared reflectivity for wavelengths higher than $1 \mu \mathrm{m}$ [18]. Therefore, it is used widely as transparent conducting oxide.

The first method is the CBD to grow $\mathrm{ZnO}$ seed layers on ITO substrates (ZSCBD). ITO substrates were immersed in aqueous solution of $0.1 \mathrm{M}$ Zinc Acetate Dihydrate $\left(\mathrm{Zn}\left(\mathrm{CH}_{3} \mathrm{COO}\right)_{2} \cdot 2 \mathrm{H}_{2} \mathrm{O}\right.$, Sigma-Aldrich) and $0.1 \mathrm{M}$ hexamethylenetetramine $\left(\mathrm{C}_{6} \mathrm{H}_{12} \mathrm{~N}_{4}\right.$, Sigma-Aldrich $)$ (VL: 1:1) at room temperature for $15 \mathrm{~min}$. After immersing process, substrates are heated at $100{ }^{\circ} \mathrm{C}$ for 15 min. The process is repeated 10 times for achieving seed layers.

Another method is $\mathrm{SC}$ to obtain $\mathrm{ZnO}$ seed layers on ITO substrates (ZSSC). $1 \mathrm{~g}$ Zinc Nitrate Hexahydrate 
$\left(\mathrm{Zn}\left(\mathrm{NO}_{3}\right)_{2} \cdot 6 \mathrm{H}_{2} \mathrm{O}\right.$, Sigma-Aldrich) was dissolved in $10 \mathrm{ml}$ ethanol $\left(\mathrm{C}_{2} \mathrm{H}_{5} \mathrm{OH}\right)$. Ammonia $(26 \%)$ was added until getting a clear solution. After preparing the solution, $\mathrm{ZnO}$ seed layers were deposited on ITO substrates. The rotation rate was $3000 \mathrm{rpm}$ up to $25 \mathrm{~s}$. The as-deposited $\mathrm{ZnO}$ seed layers were sintered at $220{ }^{\circ} \mathrm{C}$ for about $2-3$ minutes and deposited procedure was repeated at 10 times. Seed layers were annealed at $400{ }^{\circ} \mathrm{C}$ for $2 \mathrm{~h}$.

$\mathrm{ZnO}$ arrays were grown by Hydrothermal Synthesis method at $90{ }^{\circ} \mathrm{C}$ on the seed layers. A prepared solution for hydrothermal process contained $0.1 \mathrm{M}$ Zinc Nitrate Hexahydrate and $0.1 \mathrm{M}$ hexamethylenetetramine (VL: $1: 1)$. The solution was transferred into Teflon-lined stainless steel autoclave and the seed layers were remained in the autoclave at $90{ }^{\circ} \mathrm{C}$ for $4 \mathrm{~h}$.

The properties of $\mathrm{ZnO}$ micro-nanorod arrays were characterized by XRD, SEM and UV-Vis measurements.

The structural properties of samples were studied using a Panalytical Empyrean X-ray diffractometer operated at $45 \mathrm{kV}, 40 \mathrm{~mA}$ with $\mathrm{CuK \alpha}$ radiation $(\lambda=1.5406 \AA)$. The morphologies of the samples were studied using a FEI Quanta 550 FESEM Model Scanning Electron Microscope. The optical properties of the samples were studied using a PerkinElmer Lambda-35 UV-Vis spectrophotometer.

\section{RESULTS AND DISCUSSION}

Fig. 1 shows the XRD patterns of the seed layers. The peak of ZSSC along the (002) plane which is in good agreement with wurtzite $\mathrm{ZnO}$ crystal structure [13], is sharper than the same peak of ZSCBD for the same plane. Furthermore, ITO peaks have emerged sharply in each seed layer. ZSSC, which is thinner and smoother, has given higher ITO peak intensity than the ZSCBD.

Fig. 2 shows the XRD patterns of the $\mathrm{ZnO}$ micronanorod arrays. (002) diffraction peak of $\mathrm{ZnO}$ micronanorod arrays grown on seed layer synthesized by using SC (ZRSC) has a much higher intensity than (002) diffraction peak of $\mathrm{ZnO}$ arrays grown on seed layer synthesized by using CBD (ZRCBD). Intensities of the other peaks are rather low than (002) peak for each sample and intensities of the other peaks for ZRSC are lower than ZRCBD. The obtained single crystalline wurtzite $\mathrm{ZnO}$ structure is in good agreement with the literature [19, 20]. Additionally, it is reported that 2 theta degree of (002) peak for $\mathrm{ZnO}$ hydrophobic film growth by using CBD is identified between $50^{\circ}-55^{\circ}$ with highly intensity [19]. However, 2 theta degrees of (002) peaks for ZRCBD and ZRSC which is identified approximately at $35^{\circ}$, is in good agreement with hydrothermal studies $[11,21]$.

The crystallize sizes were calculated using Scherer equation:

$\mathrm{D}=\mathrm{k} \lambda /(\beta \cos \theta)$,

where $\lambda$ is the $\mathrm{X}$-ray wavelength; $k$ is the constant $(0.9$ value); $\theta$ is the Bragg angle and $\beta$ is the full width at half maximum. The results are shown in Table 1 . The diffraction peaks of wurtzite (hexagonal crystal system) structure are detected, and the peak positions are in good agreement with the values of data card (98-016-1836) [22].

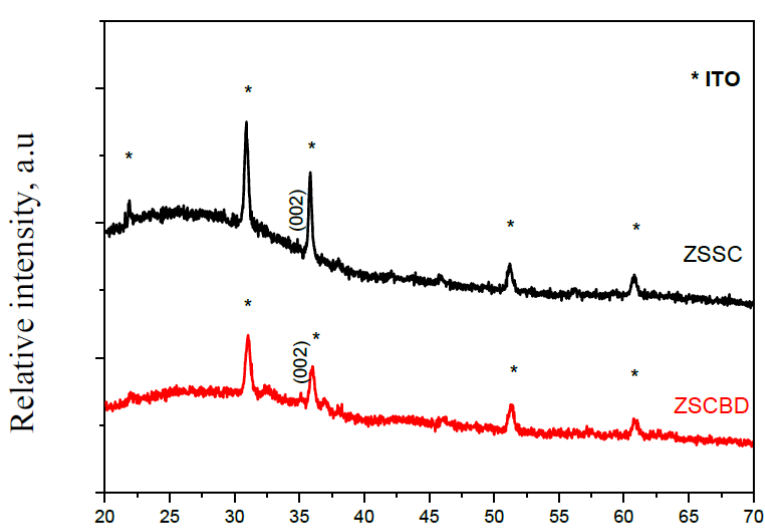

2 theta, degrees

Fig.1. $\mathrm{XRD}$ spectra of $\mathrm{ZnO}$ seed layers

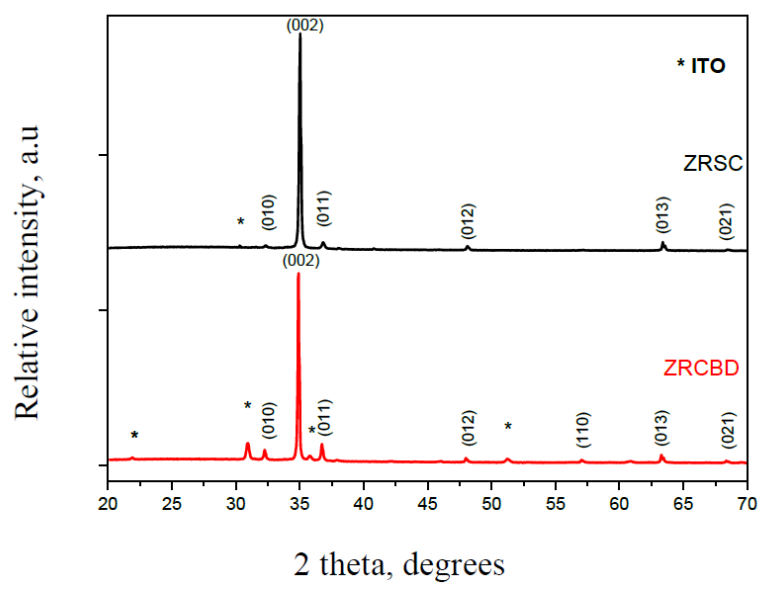

Fig. 2. XRD spectra of $\mathrm{ZnO}$ micro-nanorod arrays

SEM images of seed layer are shown in Fig. 3 for different magnifications. It is obvious that ZSSC has a smoother and less rough surface than ZSCBD.

SEM images of $\mathrm{ZnO}$ micro-nanorod arrays are shown in Fig. 4 for different magnifications. ZRSC exhibits vertically well-arranged growth direction, which are consistent with the XRD results, while ZRCBD exhibits randomly flower like structure in micro-nano size. Vertically well-aligned ZRSC arrays oriented at (002) plane and (0001) direction are in good agreement with the literature [11,21]. Most of these rods have approximately $15-20^{\circ}$ deflection angles from the vertical axis and this result is in good agreement with the literature [21]. However, flower like ZRCBD arrays were grown randomly oriented due to high porosity seed layer.

The effects of the differences in the surface morphology on optical characteristics and optical bandgap are discussed in optical results.

Fig. 5 and Fig. 6 show the UV-Vis absorption and optical bandgap spectra of the $\mathrm{ZnO}$ micro-nanorod arrays on different seed layers. In Fig. 6, blue lines are fitting line for curve to determine the optical bandgap values.

As seen from Fig. 5 and Fig. 6, the UV-Vis absorption spectra of two kinds of samples were different intensity peaks. But, $\mathrm{ZnO}$ arrays displayed a sharp absorption onset at about $422 \mathrm{~nm}$ for each sample. The optical bandgap for ZRSC $(3.15 \mathrm{eV})$ is in better agreement with the literature $[23,24]$ than optical bandgap for ZRCBD $(3.12 \mathrm{eV})$. 
Table 1. XRD data of $\mathrm{ZnO}$ micro-nanorod arrays

\begin{tabular}{|c|c|c|c|c|c|c|c|c|c|c|}
\hline \multicolumn{3}{|c|}{$\begin{array}{l}\text { ICSD collection card: } \\
98-016-1836 \text { [22] }\end{array}$} & \multicolumn{4}{|c|}{ XRD Parameters of ZRCBD } & \multicolumn{4}{|c|}{ XRD Parameters of ZRSC } \\
\hline $2 \theta,^{\circ}$ & $\mathrm{d}, \AA$ & $\mathrm{h} \mathrm{k1}$ & $2 \theta,^{\circ}$ & FWHM & $\mathrm{d}, \AA$ & $\mathrm{D}, \mathrm{nm}$ & $2 \theta,^{\circ}$ & FWHM & $\mathrm{d}, \AA$ & $\mathrm{D}, \mathrm{nm}$ \\
\hline 31.439 & 2.8431 & 010 & $32.240(1)$ & $0.144(8)$ & 2.77437 & 60.9 & $32.309(5)$ & $0.24(2)$ & 2.76858 & 30.7 \\
\hline 34.889 & 2.5695 & 002 & $34.8740(1)$ & $0.1056(7)$ & 2.57060 & 186.6 & $34.9897(2)$ & $0.1434(6)$ & 2.56237 & 84.5 \\
\hline 36.074 & 2.4878 & 011 & $36.7126(7)$ & $0.130(8)$ & 2.44597 & 73.9 & $36.803(2)$ & $0.236(6)$ & 2.44017 & 38.5 \\
\hline 47.666 & 1.9063 & 012 & $47.99(1)$ & $0.1(2)$ & 1.89436 & 78.7 & $48.093(2)$ & $0.153(7)$ & 1.89040 & 67.0 \\
\hline 55.973 & 1.6415 & 110 & $57.034(3)$ & $0.18(4)$ & 1.61347 & 49.1 & $57.08(2)$ & $0.60(8)$ & 1.61222 & 11.6 \\
\hline 63.335 & 1.4672 & 013 & $63.274(4)$ & $0.14(4)$ & 1.46853 & 76.9 & $63.3856(9)$ & $0.133(3)$ & 1.46622 & 79.2 \\
\hline 68.418 & 1.3701 & 021 & $68.354(4)$ & $0.14(6)$ & 1.37125 & 82.0 & $68.447(5)$ & $0.20(1)$ & 1.36960 & 54.2 \\
\hline
\end{tabular}
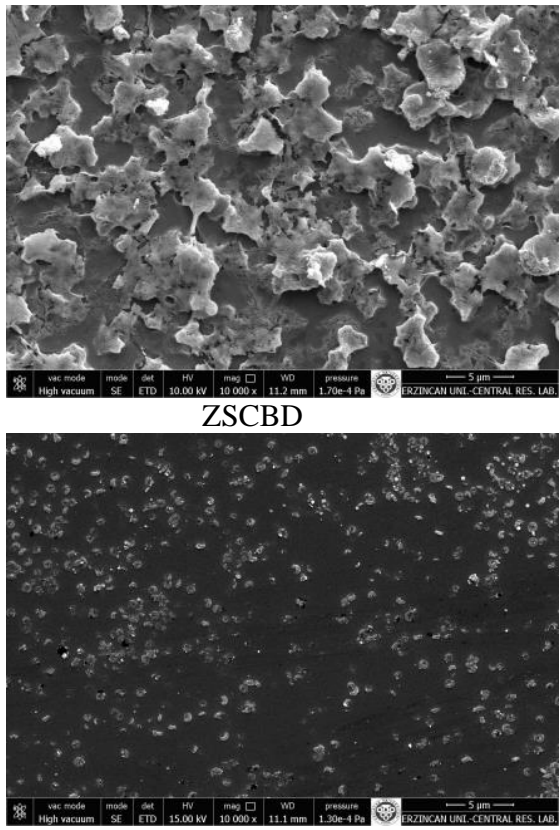

ZSSC

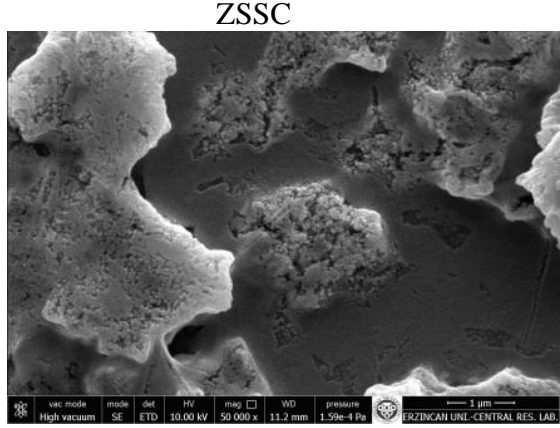

ZSCBD

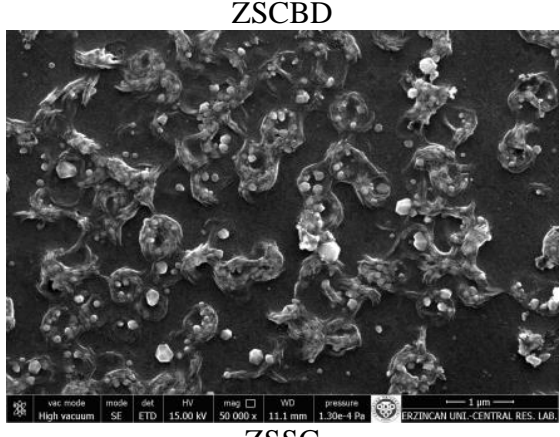

ZSSC

Fig. 3. SEM images (10000 - 50000 magnifications) of $\mathrm{ZnO}$ seed layers

Also, it is reported that high quality $\mathrm{ZnO}$ arrays have a narrower bandgap than bulk $\mathrm{ZnO}(3.37 \mathrm{eV})$ and it is explained that while large bandgap for $\mathrm{ZnO}$ structure limits its photoresponce to only the UV solar spectrum region. $\mathrm{ZnO}$ structure with narrow bandgap provides effectively to be used solar energy for solar applications [25].

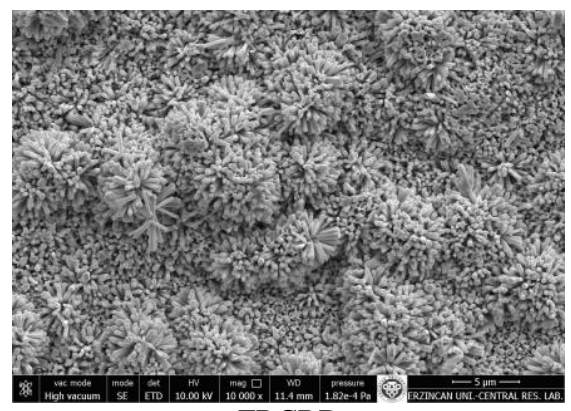

ZRCBD

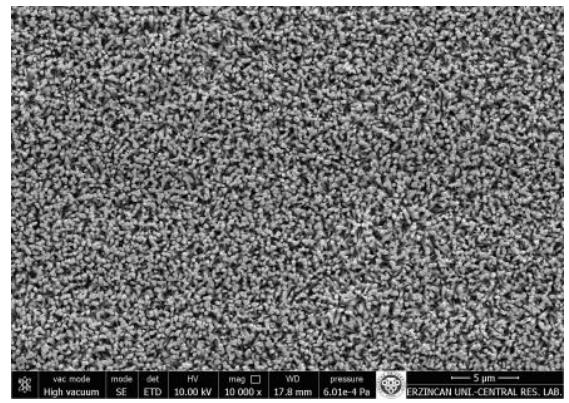

ZRSC

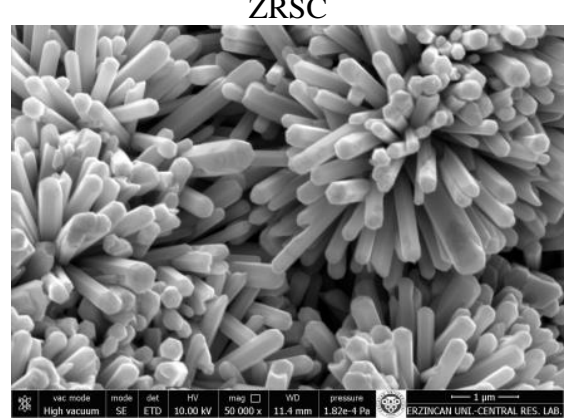

ZRCBD

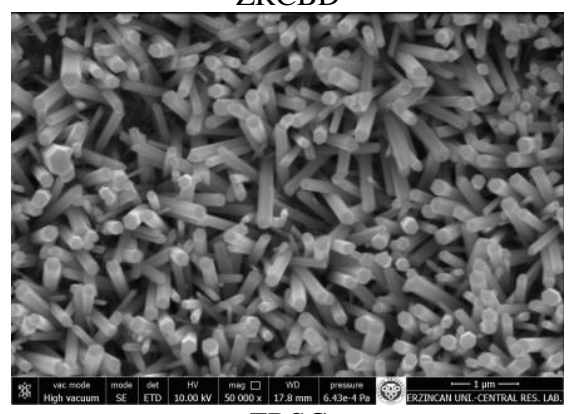

ZRSC

Fig. 4. SEM images (10000 - 50000 magnifications) of $\mathrm{ZnO}$ micro-nanorod arrays 
As seen from results, the seed layer played important roles in morphology, crystal structure and optical properties of $\mathrm{ZnO}$ micro-nanorod arrays.

The reason for the strong tendency to uniformity is the way the two main forces balance; they are the rotationinduced centrifugal force, which drives radially outward flow, and the resisting viscous force, which acts radially inward for the SC method [26]. Besides, the major problem of the CBD method is the inefficiency of the process which converts the precursor materials into useful deposits; firstly, homogeneous nucleation leads to rapid formation of large particles throughout the solution, as precipitate, conversely, heterogeneous nucleation occurs at the substrate surface and particles grow slowly to form a film [27]. As a result, morphology of seed layer is strongly related with coating method.

Therefore, ZSSC has smooth and uniform surface that is provided to be synthesized vertically aligned high crystallinity wurtzite $\mathrm{ZnO}$ rod arrays on this seed layer. ZSCBD has highly porosity that is caused to be synthesized flower like and randomly oriented $\mathrm{ZnO}$ rod arrays on this seed layer.

Additionally, it is reported that highly porous surfaces play an important role in the synthesis of $\mathrm{ZnO}$ flower like rod arrays [28]. Porous $\mathrm{ZnO}$ nanostructures exhibit highly sensitive performance for metal oxide gas sensor [29], while vertically aligned nanorod arrays are promising candidates for optoelectronic applications [30].

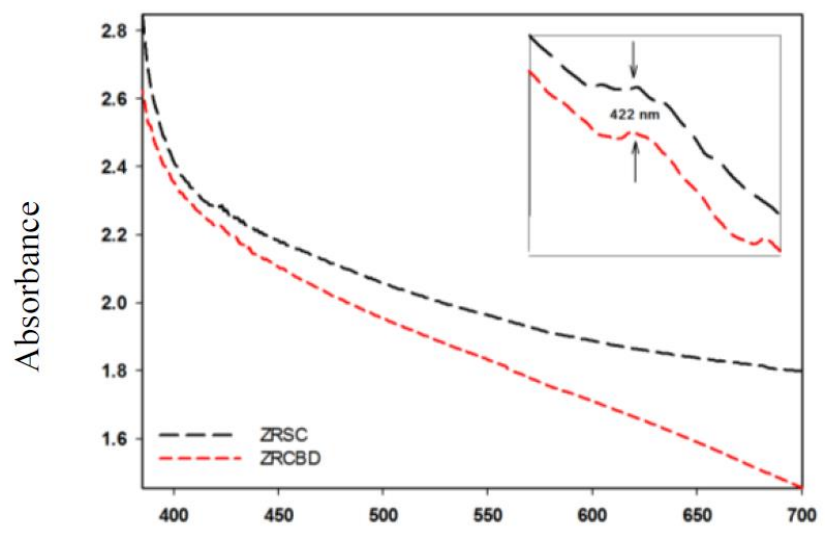

Wavelength, nm

Fig. 5. UV-Vis absorption spectra of $\mathrm{ZnO}$ micro-nanorod arrays

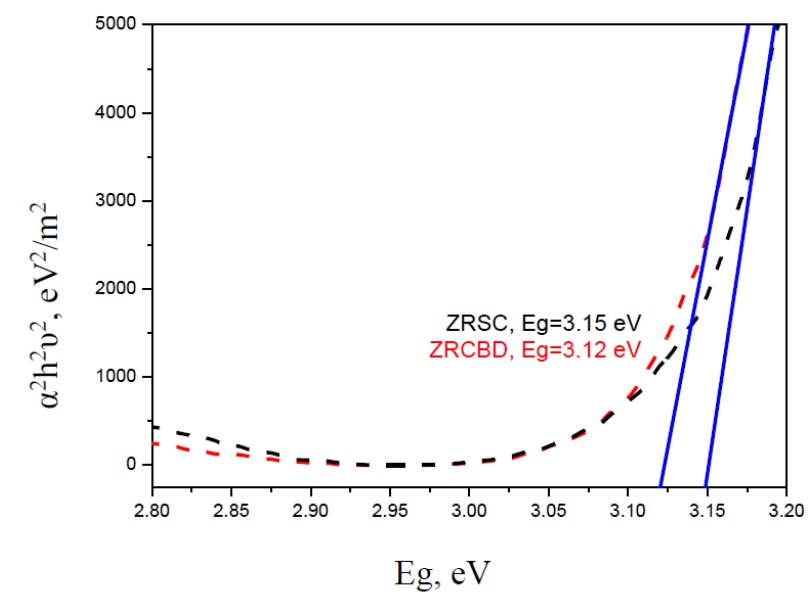

Fig. 6. Optical bandgap spectra of $\mathrm{ZnO}$ micro-nanorod arrays

\section{CONCLUSIONS}

In this study, $\mathrm{ZnO}$ micro-nanorod arrays were synthesized on seed layers that were prepared by using two different methods.

The Spin Coating is a better seed layer growth method than the Chemical Bath Deposition method to grow vertically and well-arranged single crystalline wurtzite $\mathrm{ZnO}$ micro-nanorod arrays by hydrothermal method. Also, the optical measurements show that optical bandgap of $\mathrm{ZnO}$ micro-nano arrays grown on SC seed layer is in good agreement with the literature. Furthermore, the Chemical Bath Deposition method is good seed layer method to obtain flower like $\mathrm{ZnO}$ nanostructures.

\section{Acknowledgments}

This work was supported by Erzincan University Research Fund (EÜBAP), Project Number 12.01.12.

\section{REFERENCES}

1. Guo, X.D., Pi, H.Y., Zhao, Q.Z., Li, R.X. Controllable Growth of Flowerlike ZnO Nanostructures by Combining Laser Direct Writing and Hydrothermal Synthesis Materials Letters 66 (1) 2012: pp. 377-381.

2. Li, Z., Huang, X., Liu, J., Li, Y., Li, G. Morphology Control and Transition of $\mathrm{ZnO}$ Nanorod Arrays by a Simple Hydrothermal Method Materials Letters $62(10-11)$ 2008: pp. $1503-1506$.

3. Yi, S.H., Choi, S.K., Jang, J.M., Kim, J.A., Jung, W.G. Low-Temperature Growth of $\mathrm{ZnO}$ Nanorods by Chemical Bath Deposition Journal of Colloid and Interface Science 313 (2) 2007: pp. 705-710.

4. Rai, P., Song, H.M., Kim, Y.S., Song, M.K., Oh, P.R., Yoon, J.M., Yu, Y.T. Microwave Assisted Hydrothermal Synthesis of Single Crystalline ZnO Nanorods for Gas Sensor Application Materials Letters 68 2012: pp. 90-93.

5. Qin, Z., Huang, Y., Qi, J., Li, H., Su, J., Zhang, Y. Facile Synthesis and Photoelectrochemical Performance of the Bush-Like ZnO Nanosheets Film Solid State Sciences 14 (1) 2012: pp. $155-158$.

http://dx.doi.org/10.1016/j.solidstatesciences.2011.11.014

6. Tan, W.K., $\quad$ Abdulrazak, K., Lockman, Z., Kawamura, G., Muto, H., Matsuda, A. Synthesis of $\mathrm{ZnO}$ Nanorod-Nanosheet Composite via Facile Hydrothermal Method and Their Photocatalytic Activities under VisibleLight Irradiation Journal of Solid State Chemistry 211 2014: pp. $146-153$. http://dx.doi.org/10.1016/j.jssc.2013.12.026

7. Malek, M.F., Sahdan, M.Z., Mamat, M.H., Musa, M.Z., Khusaimi, Z., Husairi, S.S., Md Sin, N.D., Rusop, M. A Novel Fabrication of MEH-PPV/Al:ZnO Nanorod Arrays Based Ordered Bulk Heterojunction Hybrid Solar Cells Applied Surface Science 275 2013: pp. 75-83. http://dx.doi.org/10.1016/j.apsusc.2013.01.119

8. Alvi, N.H., Hassan, W., $\quad$ Farood, B., $\quad$ Nur, O., Willander, M. Influence of Different Growth Environments on the Luminescence Properties of $\mathrm{ZnO}$ Nanorods Grown by the Vapor-Liquid-Solid (VLS) Method Materials Letters 106 2013: pp. 158-163. http://dx.doi.org/10.1016/j.matlet.2013.04.074

9. Phan, T.L., Yu, S.C., Vincent, R., Dan, N.H., Shi, W.S. Photoluminescence Properties of Various CVD-Grown ZnO 
Nanostructures Journal of Luminescence $130(7)$ 2010: pp. $1142-1146$.

http://dx.doi.org/10.1016/j.jlumin.2010.02.010

10. Kim, S.J., Kim, H.H., Kwon, J.B., Lee, J.G., Hoan, B.O., Lee, S.G., Lee, E.H., Park, S.G. Novel Fabrication of Various Size $\mathrm{ZnO}$ Nanorods Using Hydrothermal Method Microelectronic Engineering 87 (5-8) 2010: pp. $1534-1536$.

11. Yuan, Z., Yu, J., Jiang, Y. Growth of Diameter-Controlled $\mathrm{ZnO}$ Nanorod Arrays by Hydrothermal Technique for Polymer Solar Cell Application Energy Procedia 12 2011: pp. $502-507$.

12. Shanmuganathan, G., Shameem Banu, I.B., Krishnan, S., Ranganathan, B. Influence of K-Doping on the Optical Properties of $\mathrm{ZnO}$ Thin Films Grown by Chemical Bath Deposition Method Journal of Alloys and Compounds 562 2013: pp. 187-193.

13. Yılmaz, M. Characteristic Properties of Spin Coated $\mathrm{ZnO}$ Thin Films: The Effect of Ni Doping Physica Scripta 89 (9) 2014: pp. $1-7$.

14. Jung, H.J., Lee, S., Yu, Y., Hong, S.M., Choi, H.C., Choi, M.Y. Low-Temperature Hydrothermal Growth of $\mathrm{ZnO}$ Nanorods on Sol-Gel Prepared $\mathrm{ZnO}$ Seed Layers: Optimal Growth Conditions Thin Solid Films 524 2012: pp. $144-150$. http://dx.doi.org/10.1016/j.tsf.2012.10.007

15. Yi, F., Huang, Y., Zhang, Z., Zhang, Q., Zhang, Y. Photoluminescence and Highly Selective Photoresponse of $\mathrm{ZnO}$ Nanorod Arrays Optical Materials 35 (8) 2013: pp. $1532-1537$. http://dx.doi.org/10.1016/j.optmat.2013.03.018

16. Thangavel, R., Chang, Y.C. Investigations on Structural, Optical and Electrical Properties of p-Type ZnO Nanorods Using Hydrothermal Method Thin Solid Films 520 (7) 2012: pp. $2589-2593$.

http://dx.doi.org/10.1016/j.tsf.2011.11.010

17. Xian, F., Bai, W., Xu, L., Wang, X., Li, X. Controllable Growth of $\mathrm{ZnO}$ Nanorods by Seed Layers Annealing Using Hydrothermal Method Materials Letters 108 2013: pp. 46-49.

18. Nadaud, N., Lequeux, N., Nanot, M., Jove, J., Roisnel, T. Structural Studies of Tin-Doped Indium Oxide (ITO) and $\mathrm{In}_{4} \mathrm{Sn}_{3} \mathrm{O}_{12} \quad$ Journal of Solid State Chemistry 135 1998: pp. $140-148$. http://dx.doi.org/10.1006/jssc.1997.7613

19. Shinde, V.R., Lokhande, C.D., Mane, R.S., Han, S.H. Hydrophobic and Textured $\mathrm{ZnO}$ Films Deposited by Chemical Bath Deposition: Annealing Effect Applied Surface Science $245(1-4)$ 2005: pp. 407-413.

20. Jiang, S., Ren, Z., Gong, S., Yin, S., Yu, Y., Li, X., Xu, G., Shen, G., Han, G. Tunable Photoluminescence Properties of Well-Aligned ZnO Nanorod Array by Oxygen
Plasma Post-Treatment Applied Surface Science

2014: pp. $252-256$

http://dx.doi.org/10.1016/j.apsusc.2013.10.146

21. Zeng, J.L., Zhang, X.W., Tan, J.Z.Y., Bian, J.C., Li, Z., Chen, Z.D., Peng, R.Q., He, H.Y., Wang, J., Yang, F. Full-Color Photoluminescence of $\mathrm{ZnO}$ Nanorod Arrays Based on Annealing Processes Journal of Luminescence 135 2013: pp. $201-205$.

22. Fan, X.F., Sun, H.D., Shen, Z.X., Kuo, J.L., Lu, Y.M. A First-Principle Analysis on the Phase Stabilities, Chemical Bonds and Band Gaps of Wurtzite Structure $\mathrm{A}_{x} \mathrm{Zn}_{1-\mathrm{x}} \mathrm{O}$ Alloys $(\mathrm{A}=\mathrm{Ca}, \mathrm{Cd}, \mathrm{Mg}) \quad$ Journal of Physics: Condensed Matter 20 (23) 2008: pp. 1-9.

http://dx.doi.org/10.1088/0953-8984/20/23/235221

23. Guo, T.H., Liu, Y., Zhang, Y.C., Zhang, M. Green Hydrothermal Synthesis and Optical Absorption Properties of $\mathrm{ZnO}_{2}$ Nanocrystals and $\mathrm{ZnO}$ Nanorods Materials Letters 65 (4) 2011: pp. 639-641. http://dx.doi.org/10.1016/j.matlet.2010.11.032

24. Zhang, H., Jin, S., Duan, G., Wang, J., Cai, W. Controllable Synthesis of Well-Aligned $\mathrm{ZnO}$ Nanorod Arrays on Varying Substrates via Rapid Electrodeposition Journal of Materials Science \& Technology $30(11)$ 2014: pp. $1118-1123$. http://dx.doi.org/10.1016/j.jmst.2014.04.006

25. Cheng, Y., Wang, J., Jönsson, P.G., Zhao, Z. Optimization of High-Quality Vertically Aligned ZnO Rod Arrays by the Response Surface Methodology Journal of Alloys and Compounds 626 2015: pp. 180-188.

26. Scriven, L.E. Physics and Applications of Dip Coating and Spin Coating Materials Research Society Symposium Proceedings 121 1988: pp. 717-729.

27. Kathalingam, A., Ambika, N., Kim, M.R., Elanchezhiyan, J., Chae, Y.S., Rhee, J.K. Chemical Bath Deposition and Characterization of Nanocrystalline $\mathrm{ZnO}$ Thin Films Materials Science-Poland 28 (2) 2010: pp. $513-522$.

28. Dalvand, R., Mahmud, S., Rouhi, J. Direct Growth of Flower-Like $\mathrm{ZnO}$ Nanostructures on Porous Silicon Substrate Using a Facile Low-Temperature Technique Materials Letters 160 2015: pp. 444-447. http://dx.doi.org/10.1016/j.matlet.2015.08.029

29. Meng, F., Hou, N., Jin, Z., Sun, B., Li, W., Xiao, X., Wang, C., Li, M., Liu, J. Sub-ppb Detection of Acetone Using Au-Modified Flower-Like Hierarchical $\mathrm{ZnO}$ Structures Sensors and Actuators B: Chemical 219 2015: pp. 209-217. http://dx.doi.org/10.1016/j.snb.2015.04.132

30. Liu, Y., Liu, A., Hu, Z., Sang, Y. Characterization of Optoelectronic Properties of the $\mathrm{ZnO}$ Nanorod Array Using Surface Photovoltage Technique Applied Surface Science 257 (4) 2010: pp. $1263-1266$. http://dx.doi.org/10.1016/j.apsusc.2010.08.040 